\title{
Selective Acetylation of 2-Naphthol to 2-Naphthyl Acetate with Ni Homogeneous Catalysts: An Environmentally Friendly Protocol
}

\author{
Ateeq Rahman ${ }^{1,}$ *, Veikko Uahengo ${ }^{1}$, Daniel Shipwiisho Likius ${ }^{1}$, Mathew Mupa ${ }^{2}$ \\ ${ }^{1}$ Department of Chemistry and Biochemistry, University of Namibia, Windhoek, Namibia \\ ${ }^{2}$ Department of Chemistry, Bindura University of Science Education, Bindura, Zimbabwe
}

Email address:

ateeqr786@yahoo.com (A. Rahman)

*Corresponding author

\section{To cite this article:}

Ateeq Rahman, Veikko Uahengo, Daniel Shipwiisho Likius, Mathew Mupa. Selective Acetylation of 2-Naphthol to 2-Naphthyl Acetate with Ni Homogeneous Catalysts: An Environmentally Friendly Protocol. Science Journal of Chemistry. Vol. 5, No. 4, 2017, pp. 47-50. doi: $10.11648 /$ j.sjc.20170504.11

Received: June 2, 2017; Accepted: July 11, 2017; Published: August 10, 2017

\begin{abstract}
An efficient, selective and simple route for the synthesis of 2-Naphthyl acetate has been developed. In reflux conditions the acetylation of 2-naphthol acetylation with a catalytic amount of Nickel nitrate catalysts afforded 2-Naphthyl acetate in moderate to excellent yields. Nickel nitrate showed the best catalytic performance compared to other Nickel salts. Different weights of nickel salts have been evaluated for the title reaction with $30 \mathrm{mg} \mathrm{NiNO}_{3}$ afforded the Best conversions. Different acylating reagents were evaluated acetic acid, acetyl chloride and acetic anhydride, and it was observed that acetic acid was the best acetylating reagent. The protocol has advantages including short reaction times, high chemoselectivity towards acylated product simple work-up. Additionally, nickel nitrate, other additives are not required to enhance the reactions.
\end{abstract}

Keywords: Nickel Nitrate, Acetylation, Homogeneous Catalysts, 2-Naphthol, 2-Naphthyl Acetate

\section{Introduction}

Acetylation is one of the fundamental reactions in organic chemistry and can be carried out by a wide variety of reagents [1]. Traditionally, a greater than stoichiometric amount of Lewis acids such as $\mathrm{AlCl}_{3}, \mathrm{BF}_{3}, \mathrm{FeCl}_{3}, \mathrm{TiCl}_{4}$, $\mathrm{SnCl}_{2}$, [2] is required to mediate the reaction; the catalystis often not recovered or is not reused [3]. Since the traditional reaction is extremely sensitive to water, it must be carried out under a dry atmosphere, using anhydrous substrates and catalysts [4-5]. In addition, typical procedures employ an acid chloride as the acylating reagent, which is usually prepared from a carboxylic acid and thionyl chloride, releasing $\mathrm{HCl}$ and $\mathrm{SO}_{2}$ as by-products. It would be preferable if carboxylic acids are used in place of acid chlorides because the use of carboxylic acids as acylating agents produces water as the sole by-product. Therefore, acylation using a carboxylicacid can shorten the synthetic route and is environmentally preferable. Friedel-Crafts acylations using carboxylic acids have been studied extensively in the presence of catalysts such as: zeolites, [6] Montmorillonite, [7] alumina / TFAA, [8] aluminum dodeca tungsto phosphate / TFAA [8] $\mathrm{MeSO}_{3} \mathrm{H} /$ graphite [9] $\mathrm{P}_{2} \mathrm{O}_{5} / \mathrm{SiO}_{2}$ [10] $\mathrm{Tf}_{2} \mathrm{O}$ [11] TFAA [12] $\mathrm{Pd}(\mathrm{OAc})_{2} /$ TFAA [13] and rhodium [14]. Though, the use of stoichiometric amount of additional TFAA or harsh reaction conditions is often required. Tributyl phosphine was introduced as a less basic catalyst than amines in the acetylation of alcohols [28-29]. Other metal salts such as $\mathrm{LiClO}_{4}$ [36], $\mathrm{CoCl}_{2}$ [37], and $\mathrm{Mg}\left(\mathrm{ClO}_{4}\right)_{2}$ [38] have also been successfully have been reported to show catalytic activity toward the acetylation of alcohols with acid anhydride. Number of lewis acids such as TMSCl [15-16] $\mathrm{MoO}_{2} \mathrm{Cl}_{2}$ [17] $\mathrm{ErCl}_{3}$ [18] $\mathrm{RuCl}_{3}$ [19] $\mathrm{ZrOCl}_{2}$ [20] $\mathrm{Zn}\left(\mathrm{ClO}_{4}\right)_{2}$ [21] $\mathrm{TiCl}_{4}+\mathrm{AgClO}_{4}$ [22]. Since a few past years, it has been reported that several metal triflates such as $\mathrm{In}(\mathrm{OTf})_{3}[30]$, $\mathrm{Bi}(\mathrm{OTf})_{3}$ [31], $\mathrm{ZrO}(\mathrm{OTf})_{2}$ [32], Gd(OTf $)_{3}$ [33], as well as $\mathrm{Me}_{3} \mathrm{SiOTf}$ [34-35] are excellent catalysts for efficient acetylation of various types of structurally diverse alcohols with aceticanhydride. $\mathrm{Cu}(\mathrm{OTf})_{2}\left(\mathrm{TfCF}_{3} \mathrm{SO}_{2}\right)$ [23], $\mathrm{Er}(\mathrm{OTf})_{3}$ [24], $\mathrm{Al}(\mathrm{OTf})_{3}$ [25], Ti-Cl ${ }_{3}(\mathrm{OTf})$ [9], $\mathrm{Ce}(\mathrm{OTf})_{3}$ [21], 


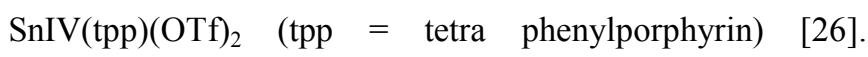
Particularly, $\mathrm{Sc}(\mathrm{OTf})_{3}$ [27] a commercially available and moisture-stable lewis acid, is extremely active for this reaction. Unfortunately, due to the high price of scandium salts and its intolerance toward various functional groups, $\mathrm{Sc}(\mathrm{OTf})_{3}$ is limited in application. TMSOTf is another catalyst for acylation of alcohols and phenols [24]. Additionally, the requirement for an expensive catalyst $\mathrm{Hf}(\mathrm{OTf})_{4}$, large amounts of volatile organic solvents, and prolonged reaction times precludes the wide use of these reagents for acetylation reactions which is a major drawback [24]. Development of regio-selective reactions in organic compounds is fundamental and important viz. 2-Acylation reactions of phenol and naphthol derivatives that provide useful synthetic methods for the preparation of 2-hydroxy phenyl or 2-hydroxy naphthyl ketone derivatives [24]. Chakraborti et al [39-40] also reported a number of good catalytic systems for the acetylation/acylation reactions.

Ambika et al.; [41] reported Pyridine as a popular catalyst for the acetylation of alcohols using acetic anhydride, but is toxic, has a bad smell, and its high boiling point makes its removal after the reaction difficult. Pyridine is normally used in excess and because of its high boiling point its removal is difficult and can complicate product isolation if very small amount of ester has been synthesized. However, these catalyst systems suffer from some limitation such as long reaction time, high catalyst loadings, use of toxic solvent or special apparatus. Thesearch for milder and more environmentally benign conditions is, therefore, highly demanding for the synthesis of these compounds. As a part of our ongoing research devoted to the development of useful synthetic methodologies employing Ni based catalysts which was reported by Jonnalgadda et al.; [42]. The aim of this paper is to present the results of acetylation 2-naphthol, and study catalytic activity of nickel nitrate and other nickel salts. Authors further evaluated the catalytic activity of various forms of nickel nitrate, nickel sulfate, nickel acetate with different acylating agents. Authors further also tested various amounts of catalysts with nickel nitrate, nickel acetate and nickel sulfate. The reactions were performed under mild reflux conditions in acetonitrile solvent.

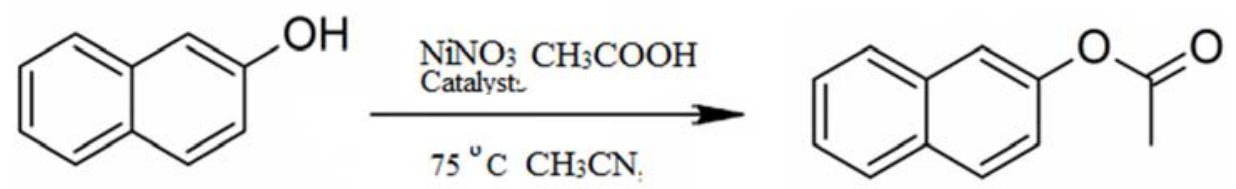

Figure 1. Reaction scheme for acetylation of 2-Naphthol.

\section{Experimental}

\subsection{Materials}

Acetic anhydride, dichloromethane, nickel nitrate hexahydrate, ethyl acetate (BDH Chemicals, England), silica gel (ICN Pharamacitical Gmbh, Germany), sodium sulfate anhydrous (Fluka Chemika), phenol (Merck, India), hexanol (Winlab, UK), 2-naphthol (Riedel-de Haen, Germany), 2naphthol (Hopkin \& Williams, England), 2, 4, 6-trimethyl phenol, 3, 4-dimethylphenol (Fluka AG Switzerland) were used as received.

\subsection{Typical Reaction Procedure}

To 2-Naphthol $(2.0 \mathrm{mmol})$ dissolved in $10.0 \mathrm{~mL}$ acetonitrile solvent acatalyst (30mg) was added. This was followed by slow addition of acetic acid $(1.5 \mathrm{mmol})$ at room temperature was added at room temperature over a period of $5 \mathrm{~min}$. The reaction mixture was refluxed continuously until all the starting material reacted and The reaction was monitored by TLC. The reaction mixture is quenched by adding de-ionized water and extracted with ethyl acetate. The organic layer was dried on sodium sulfate and the was solvent evaporated on rota-vapor to give a crude product of 2-naphthyl acetate which is then purified using column chromatography to afford pure 2-naphthylacetate product. The final product was characterized by ${ }^{1} \mathrm{H}(400 \mathrm{MHz}$ Bruker Instrument). GC-MS samples were run on a Agilent 6890 GC/5973, MS Column: J\&W HP5-MS. GC results were characterized on GC System 6820, Agilent Technologies equipped with flame ionization detection (FID) and a carbovax OVI capillary column and compared with standard sample.

\section{Results and Discussion}

Table 1 shows results of acetylation of 2-naphthol to 2naphthyl acetate with various $\mathrm{Ni}$ catalysts. Amongst the various $\mathrm{Ni}$ catalysts tested, $\mathrm{NiNO}_{3}$ offers a superior performance in terms of reactant conversion and selectivity to the desired product. In order to evaluate the best catalysts however, $\mathrm{Ni}-\mathrm{SO}_{4}$, and $\mathrm{Ni}$ acetate also showed good performances. Owing to the industrial demand catalytic amount of $\mathrm{Ni}$ is more valuable due to the generation of copious of amount of waste generated when stoichiometric amount is used, hence authors report a simple and selective $\mathrm{Ni}$ homogeneous catalysts in catalytic mount for acetylation reaction of 2-naphthol to 2-naphthyl acetate. A model reaction have been evaluated for acetylation reaction with $\mathrm{NiSiO}_{2}$ catalysts and various homogeneous nickel catalysts for the title reaction showed that Ni-nitrate $30 \mathrm{mg}$ is the active catalysts for the title reaction when acetic acid is used as acylating agent. Authors report here the better conversions of 2-naphthol to 2-naphthyl acetate in $90 \%$ conv with catalytic $30 \mathrm{mg}$ amount of $\mathrm{NiNO}_{3}$ catalysts. Hence F. N. Lugenwa et al; [43] reported the synthesis of 2-naphthyl acetate was started from the 2-naphthol with acetic anhydride in the presence of $\mathrm{K}_{2} \mathrm{CO}_{3}$ few more additives were utilized in 
the reaction to afford 2-naphthyl acetate with 92\% conv compared to Lugenwa et al [43]. When the amount of nickel catalysts is increased to $35 \mathrm{mg}$ it was observed that the conversions were reduced to between $80 \%$ and $35 \%$ this is due to more nickel content formed during the reaction. Similar trend is observed when acetic anhydride is used as acetylating agent. This is attributed with the above assumption that with increase in nickel catalysts the reaction gets less converted. When nickel acetate is used as catalysts in various amount $35 \mathrm{mg}$ and $40 \mathrm{mg}$ there was no reaction only starting material was recovered. Owing to testing with different catalysts the authors further investigated to test different acylating agent Acetic acid, acetyl chloride and acetic anhydride from these studies its evident that the best acylating agent evaluated was acetic acid with catalytic amount of $\mathrm{NiNO}_{3} 30 \mathrm{mg}$ which resulted into $90 \%$ conversion of 2-naphthol to 2-naphthyl acetate. Whereas when acetic anhydride and acetyl chloride was tested for the title reaction with Nickel nitrate 35 to $90 \%$ was observed entry no: 1-6. However, when nickel acetate was evaluated for catalytic tests with acetic anhydride it was observed that the trend changed there was no reaction only starting material was recovered this can be attributed to the steric factors of nickel acetate and acetic anhydride. Nickel sulfate was tested with acetyl chloride and reaction proceeded slowly resulting in less conversion of product. In order to find the significance and advantages of this method over previous methods of acylation, the obtained results from our method were compared with other previously reported with $\mathrm{NiSiO}_{2}$ as heterogeneous catalysts which is prepared and characterized [44] Alam. et al.; [45-47]. Due to the above-mentioned benefits (high regioselectivity and yield product), the simplicity of the reaction process and easy work-up are some advantages of our method over than other methods.

Table 1. Model reaction of 2-Naphthol with various catalytic Amountof Ni catalysts and acetylating agent.

\begin{tabular}{lllll}
\hline S. No & Catalysts & $\begin{array}{l}\text { Amount of } \\
\text { catalysts }\end{array}$ & Acylating agent & Conv\% \\
\hline 1 & $\mathrm{NiNO}_{3}$ & $20 \mathrm{mg}$ & Acetic acid & 70 \\
2 & $\mathrm{Ni} \mathrm{NO}_{3}$ & $30 \mathrm{mg}$ & Acetic acid & 90 \\
3 & $\mathrm{Ni} \mathrm{NO}_{3}$ & $35 \mathrm{mg}$ & Acetic acid & 80 \\
4 & $\mathrm{Ni} \mathrm{NO}_{3}$ & $30 \mathrm{mg}$ & Acetic anhydride & 35 \\
5 & $\mathrm{Ni} \mathrm{NO}_{3}$ & $40 \mathrm{mg}$ & Acetic anhydride & 45 \\
6 & $\mathrm{Ni} \mathrm{NO}_{3}$ & $35 \mathrm{mg}$ & Acetyl chloride & 60 \\
7 & $\mathrm{Ni} \mathrm{NO}$ & $35 \mathrm{mg}$ & Acetyl chloride & 70 \\
8 & $\mathrm{Ni}\left(\mathrm{OAc}_{3}\right)$ & $35 \mathrm{mg}$ & Acetic anhydride & $\mathrm{NR}$ \\
9 & $\mathrm{Ni}(\mathrm{OAc})$ & $40 \mathrm{mg}$ & Acetic anhydride & $\mathrm{NR}$ \\
10 & $\mathrm{Ni}-\mathrm{SO}_{4}$ & $35 \mathrm{mg}$ & Acetyl chloride & 40 \\
11 & $\mathrm{Ni}-\mathrm{SO}_{4}$ & $40 \mathrm{mg}$ & Acetyl chloride & 65 \\
12 & $\mathrm{Ni}_{4}-\mathrm{SO}_{4}$ & $35 \mathrm{mg}$ & Acetyl chloride & 73 \\
13 & $\mathrm{Ni}_{4}$ & $30 \mathrm{mg}$ & Acetyl chloride & 80 \\
\hline
\end{tabular}

2-Naphthol (2.0 mmol), $10.0 \mathrm{~mL}$ acetonitrile solvent, catalysts (30mg), acetic aceticacid $1.5 \mathrm{mmol}$.

\section{Conclusions}

In conclusion an efficient, selective method was developed for the synthesis of 2-Naphthyl acetate. It was observed that $\mathrm{Ni}$ salts $\mathrm{NiNO}_{3}, \mathrm{NiSO}_{4}, \mathrm{Ni}$ acetate have been effectively converted to the corresponding product. Catalytic amount of all these salts were evaluated and the best results were obtained with $\mathrm{NiNO}_{3} 30 \mathrm{mg}$ catalysts with acetic acid, when other acylating agents were tested acetic anhydride didn't give good results, compared to acetic acid and acetyl chloride. Hence acetic acid was more favorable for acetylation of the title reaction under reflux conditions. This protocol has advantages using of catalytic amount of $\mathrm{Ni}$ catalysts which is more useful in industry, short reaction times, high chemoselectivity towards acetylated product simple work-up. Additionally, nickel nitrate, with other additives are not required to enhance the reaction rate.

\section{References}

[1] Ogliaruso, M. A., Wolfe, J. F., Patai, S. (Eds.), 1979. In the Chemistryof Acid Derivatives: Supplement B, Part 1. Interscience, Chichester, pp. 267-490.

[2] Whitehead, A. J.; Ward, R. A.; Jones, M. F. Tetrahedron Lett. 2007, 48, 911-913.

[3] Olah, G. A. Friedel-Crafts Chemistry; John Wiley and Sons: New York, 1973.

[4] Kobayashi, S.; Sugiura, M.; Kitagawa, H. Chem. Rev. 2002, 102, 2227-2302.

[5] Sartori, G.; Maggi, R. Advances in Friedel-Crafts Acylation Reactions: Catalytic and Green Processes; Taylor \& Francis: Boca Raton, 2010.

[6] Singh, A. P.; Pandey, A. K. J. Mol. Catal. A: Chem. 1997, 123, 141-147.

[7] Chiche, B.; Finiels, A.; Gauthier, C.; Geneste, P. J. Mol. Catal. 1987, 42, 229-235.

[8] Ranu, B. C.; Ghosh, K.; Jana, U. J. Org. Chem. 1996, 61, 9546-9547.

[9] Firouzabadi, H.; Iranpoor, N.; Nowrouzi, F. Tetrahedron Lett. 2003, 44, 5343-5345.

[10] Savari, M. H.; Sharghi, H. Synthesis 2004, 2165-2168.

[11] Zarei, A.; Hajipour, A. R.; Khazdooz, L. Tetrahedron Lett. 2008, 49, 6715-6719.

[12] Khodaei, M. M.; Alizadeh, A.; Nazari, E. Tetrahedron Lett. 2007, 48, 4199-4202.

[13] Kim, S. H.; Lim, J. W.; Yu, J.; Kim, J. N. Bull. Korean Chem. Soc. 2013, 34, 2604-2608.

[14] Lu, J.; Zhang, H.; Chen, X.; Liu, H.; Jiang, Y.; Fu, H. Adv. Synth. Catal. 2013, 355, 529-536.

[15] Fukuyama, T.; Maetani, S.; Miyagawa, K.; Ryu, I. Org. Lett. 2014, 16, 3216-3219.

[16] Roux, C. L., Dubac, J., 1996. Organometallics 15, 4646-4648.

[17] Chen, C. T., Kuo, J. H., Pawar, V. D., Munot, Y. S., Weng, S. S., Ku, C. H., Liu, C. Y., 2005. J. Org. Chem. 70, 1188-1197. 
[18] Dalpozzo, R., Nino, A. D., Maiuolo, L., Oliverio, M., Procopio, A., Russo, B., Tocci, A., 2007. Aust. J. Chem. 60, 75-79.

[19] De, S. K., 2004. Tetrahedron Lett. 45, 2919-2922.

[20] Ghosh, R., Maiti, S., Chakraborty, A., 2005. Tetrahedron Lett. $45,147-151$.

[21] Bartoli, G., Dalpozzo, R., Nino, A. D., Maiuolo, L., Nardi, M., Procopio, A., Tagarelli, A., 2004. Green Chem. 6, 191-192.

[22] Miyashita, M., Shina, I., Miyoshi, S., Mukaiyama, T., 1993. Bull. Chem. Soc. Jpn. 66, 1516-1527.

[23] Tai, C. A., Kulkarni, S. S., Hung, S. C., 2003. J. Org. Chem. $68,8719-8722$.

[24] Procopio, A., Dalpozzo, R., Nino, A. D., Maiuolo, L., Russo, B., Sindona, G., 2004. Adv. Synth. Catal. 346, 1465-1470.

[25] Kamal, A., Khan, M. N. A., Reddy, K. S., Srikanth, Y. V. V., Krishnaji, T., 2007. TetrahedronLett. 48, 3813-3818.

[26] Moghadam, M., Tangestaninejad, S., Mirkhani, V., Mohammadpour-Baltork, I., Shaibani, R., 2004. J. Mol. Catal. A 219, 73-78.

[27] Ishihara, K., Kubota, M., Yamamoto, H., 1996a. Synlett 1996, 265-266.

[28] Vedejs, E.; Diver, S. T. J. Am. Chem. Soc. 1993, 115, 33583359 .

[29] Vedejs, E.; Bennett, N. S.; Conn, L. M.; Diver, S. T.; Gingras, M.; Lin, S.; Oliver, P. A.; Peterson, M. J. Reactions. J. Org. Chem. 1993, 58, 7286-7288.

[30] Chauhan, K. K.; Frost, C. G.; Love, I.; Waite, D. Synlett 1999, $1743-1744$

[31] Orita, A.; Tanahashi, C.; Kakuda, A.; Otera, J. Angrew. Chem. Int. Ed. 2000, 39, 2877-2879.

[32] Moghadam, M.; Tangestaninejad, S.; Mirkhani, V.; Mohammadpoor-Baltork, I.; Babghanbari, M.; Zarea, L. Zirconyltriflate: J. Iran. Chem. Soc. 2009, 6, 523-532.
[33] Alleti, R.; Perambuduru, M.; Samantha, S.; Prakash, V.; Reddy, V. P. J. Mol. Catal. A Chem. 2005, 226, 57-59.

[34] Procopiou, P. A.; Baugh, S. P. D.; Flack, S. S.; Inglis, G. G. A. J. Org. Chem. 1998, 63, 2342-2347.

[35] Procopiou, P. A.; Baugh, S. P. D.; Flack, S. S.; Inglis, G. G. A. J. Chem. Soc. Chem. Commun. 1996, 2625-2626.

[36] Nakae, Y.; Kusaki, I.; Sato, T. Synlett 2001, 1584-1586.

[37] Iqbal, J.; Srivastava, R. R. J. Org. Chem. 1992, 57, 20012007.

[38] Bartoli, G.; Bosco, M.; Dalpozzo, R.; Marcantoni, E.; Massaccesi, M.; Rinaldi, S.; Sambri, Synlett 2003, 39-42.

[39] Chakraborti, A. K., Shivani, R., 2006. J. Org. Chem. 71, $5785-5788$

[40] Chakraborti, A. K., Gulhane, R., 2003b. Chem. Commun., 1896-1897.

[41] Ambika; Singh, P. P.; Chauhan, S. M. S. Synth. Commun. 2008, 38, 928-936.

[42] Rahman, A., Jonnalagadda, S. B., 2009. J. Mol. Cat. A 299, 98-101.

[43] Fulgentius Nelson Lugemwa, Koonj Shaikh and Edwin Hochstedt. Catalysts 2013, 3, 954-965; doi: 10.3390/catal3040954.

[44] Manawwer Alam, Ateeq Rahman, Naser M. Alandis, Mohammed Rafi Shaik C Arabian Journal of Chemistry (2014) 7, 53-56.

[45] Zetryana Puteri Tachrim, Lei Wang, Yuta Murai, Takuma Yoshida, Natsumi Kurokawa, Fumina Ohashi, Yasuyuki Hashidoko and Makoto Hashimoto Catalysts 2017, 7, 1-28.

[46] Liu, Y.; Meng, G.; Liu, R.; Szostak, M Chem. Commun. 2016, $52,6841-6844$.

[47] Enoch A. Mensah and Lindsey Earl, Catalysts 2017, 7, 1-10. 